\title{
The impact of transvenous cardioverter-defibrillator implantation on quality of life, depression and optimism in dialysis patients: report on the secondary outcome of QOL in the randomized controlled ICD2 trial
}

\author{
Rohit J. Timal ${ }^{1}$ - Veronique de Gucht ${ }^{2}$ - Joris I. Rotmans ${ }^{3}$ - Liselotte C. R. Hensen ${ }^{1}$ - Maurits S. Buiten ${ }^{1}$. \\ Mihaly K. de Bie ${ }^{1,4} \cdot$ Hein Putter ${ }^{5} \cdot$ Martin J. Schalij ${ }^{1} \cdot$ Ton J. Rabelink $^{3} \cdot$ J. Wouter Jukema ${ }^{1}$
}

Accepted: 22 December 2020 / Published online: 19 February 2021

(c) The Author(s) 2021

\begin{abstract}
Rationale The impact of prophylactic implantable cardioverter-defibrillator (ICD) implantation on the psychological wellbeing of patients on dialysis is unknown.

Objective We aimed to identify the effect of primary ICD implantation on quality of life (QoL), mood and dispositional optimism in patients undergoing dialysis.

Methods and results We performed a prespecified subanalysis of the randomized controlled ICD2 trial. In total, 177 patients on chronic dialysis, with an age of 55-81 years, and a left ventricular ejection fraction of $\geq 35 \%$, were included in the perprotocol analysis. Eighty patients received an ICD for primary prevention, and 91 patients received standard care. The Short Form-36 (SF-36), Geriatric Depression Scale-15 (GDS-15), Revised Life Orientation Test (LOT-R) questionnaires were administered prior to ICD implantation (T0), and at 1-year follow-up (T1) to assess QoL, depression and optimism, respectively. The patients were predominantly male $(76.0 \%)$, with a median age of 67 years. Hemodialysis was the predominant mode of dialysis $(70.2 \%)$. The GDS-15 score difference (T1 - T0) was $0.5(2.1)$ in the ICD group compared with $0.3(2.2)$ in the control group (mean difference $-0.3 ; 95 \% \mathrm{CI}-1.1$ to $0.6 ; P=0.58$ ). The LOT-R score difference was $-0.2(4.1)$ in the ICD group compared with -1.5 (4.0) in the control group (mean difference $-1.1(0.8) ; 95 \% \mathrm{CI}-2.6$ to $0.4 ; P=0.17$ ). The mean difference scores of all subscales of the SF-36 were not significantly different between randomization groups. Conclusions In our population of patients on dialysis, ICD implantation did not affect QoL, mood or dispositional optimism significantly during 1-year follow-up.
\end{abstract}

Clinical Trial Registration Unique identifier: ISRCTN20479861. http://www.controlled-trials.com.

Keywords Self-report · Questionnaire · QOL · Depression · Optimism · Dialysis · ICD

Rohit J. Timal

rj_timal@hotmail.com

1 Department of Cardiology, Leiden University Medical Center, PO Box 9600, 2300 RC Leiden, The Netherlands

2 Department of Health and Medical Psychology, Leiden University, Leiden, The Netherlands

3 Department of Internal Medicine, Leiden University Medical Center, Leiden, The Netherlands

4 Department of Cardiology, Treant Zorggroep, Hoogeveen, The Netherlands

5 Department of Biomedical Data Sciences, Leiden University Medical Center, Leiden, The Netherlands

\section{Plain English summary}

We found that in patients on dialysis, implantation of an implantable cardioverter-defibrillator (ICD), which is a device that can detect and treat life-threatening heart rhythm disturbances, did not affect quality of life, mood or dispositional optimism significantly in the first year after implantation.

This new data is important because it can help physicians to decide what the best, possibly life-saving, treatment is for the approximately 2 million patients suffering from endstage kidney disease worldwide. Unfortunately, kidney failure requiring chronic dialysis treatment is associated with an 
increased risk of death and poses a major negative effect on a patient's physical and mental well-being. Preventive implantation of an ICD is not uncommon in these patients. However, the physical and psychological impact of preventive ICD implantation in these vulnerable patients is unknown. It was our goal to shed light on this by using three questionnaires (SF-36, GDS-15 and LOT-R) to map the physical and mental condition of 177 dialysis patients with an age of 55-81 years, with moderate to normal cardiac function. After filling out the questionnaires, 80 patients received an ICD, while the remaining 91 patients received standard care. One year later, all patients were asked again to complete the same three questionnaires. The results of the patients with an ICD were compared with the patients without an ICD, and we found no differences between both groups.

\section{Introduction}

The incidence of end-stage renal disease (ESRD) in the United States in 2017 was 370 per million/year [1]. ESRD poses a high burden of disease, causing physical and psychological harm [2-5]. Dialysis treatment, although life-saving, is often perceived as burdensome and negatively impacts quality of life (QOL); patients on chronic dialysis are at high risk of anxiety and depression [2, 6-12]. Patients treated with dialysis are reported to be at high risk of malignant ventricular tachyarrhythmia, although reports in the literature likely overestimate sudden cardiac death incidence in this population $[1,13,14]$. Patients known to have life-threatening arrhythmias or sudden cardiac arrest survivors may be eligible for prophylactic use of an implantable cardioverterdefibrillator (ICD) to increase life expectancy [15-18]. ICD implantation can impact psychological well-being of ICDpatients by reduction of anxiety with regard to sudden cardiac death by providing reassurance or feelings of security. On the other hand, in a subgroup of ICD-recipients, an ICD is also known to cause adverse psychological events like anxiety and depression [19-22]. ICD-patients report that living with an ICD can introduce a number of physical and psychological adjustment issues, such as fear of defibrillation, fear of driving or (temporary) loss of driver's license, fear of isolation, fear of device failure and fear of sexual- or physical activity [23]. Anxiety following device implantation could lead to alteration of leisure-time activities, e.g. refraining from enjoyed activities such as sports or hobbies, which in turn could lead to diminished QOL. Even partners of ICD patients can experience psychological distress levels as high as that of ICD-recipients [24]. An ICD shock can be experienced as extremely traumatizing. Likewise, dialysis treatment is known to cause psychological distress and to negatively impact QOL [25]. Comorbidity and the risk of complications in this vulnerable group make it unclear how these (potentially) life-saving therapies concomitantly affect physical and mental well-being, which are important but under-exposed variables. Our study group previously described the value of prophylactic ICD therapy in patients on chronic dialysis with left ventricular ejection fraction (LVEF) $\geq 35 \%$ [14]. Presently, however, the effect of an ICD implantation on the physical and mental state of patients on dialysis is unknown. The purpose of the current prespecified substudy of the randomized controlled ICD2 trial was to prospectively evaluate the impact of ICD implantation on QOL, mood or dispositional optimism in patients on maintenance dialysis.

\section{Methods}

\section{Study design}

In this report we prospectively evaluated the impact of ICD implantation on QOL, mood and dispositional optimism of patients participating in the Implantable Cardioverter-Defibrillator in Dialysis Patients (ICD2) trial [14]. Information regarding study design, randomization, study population, ICD implantation and device setup was described previously [14]. In short, ICD2 trial is an investigator-initiated, randomized, prospective, controlled study of ICD therapy versus no ICD in patients with $\mathrm{LVEF} \geq 35 \%$ on chronic dialysis. Nephrologists from 17 dialysis centers in The Netherlands referred patients for screening to Leiden University Medical Center, The Netherlands. Following inclusion, patients were asked to fill in three well-established self-rating questionnaires to monitor changes in QOL, mood and dispositional optimism using the MOS 36-item short-form health survey (SF-36, version 1), Geriatric Depression Scale-15 (GDS15) and the Revised Life Orientation Test (LOT-R), respectively. Completing the three mentioned questionnaires took approximately $30 \mathrm{~min}$.

Patients allocated to the ICD group received a Biotronik (Berlin, Germany) transvenous device that was implanted subcutaneously, under local anesthesia, at Leiden University Medical Center, The Netherlands. Longitudinal assessment of physical and mental functioning, mood and optimism was performed after 1-year follow-up, using the same previously mentioned measurement tools (SF-36, GDS-15 and the LOT-R). Our study group previously demonstrated that prophylactic ICD therapy was not associated with a reduced rate of sudden cardiac death or all-cause death in dialysis patients. The findings of the ICD2 trial do not support routine ICD implantation to prevent death in dialysis patients with $\mathrm{LVEF} \geq 35 \%$. However, in case of a class I indication, such as a previous episode of ventricular 
fibrillation, device-implantation in these patients appeared feasible. The results of the ICD2 trial were not yet known during the conduct of the QOL substudy. The ICD2 trial protocol was approved by the ethics committee of Leiden University Medical Center in April 2007. The first patient was enrolled in June 2007 and the last in January 2018. The trial was stopped early (February 2018) on the advice of the data and safety monitoring board for futility reasons, after inclusion of 188 patients. The trial is registered at the Netherlands Trial Register (http://www.controlled-trials.com/ ISRCTN20479861). All patients provided written informed consent.

\section{Population}

Inclusion criteria were age $\geq 55$ years and $<81$ years, and ESRD treated with hemodialysis or peritoneal dialysis for $\geq 90$ days. Patients on dialysis meeting the class I indication for ICD implantation were excluded. Also, patients with heart failure (New York Heart Association functional class IV) or a medical condition making 1-year survival unlikely were excluded [26, 27]. Patients with a central venous catheter were not eligible. Patients were also excluded if they were being prepared for a living kidney donation, had an acute myocardial infarction in the past 40 days, had human immunodeficiency virus, or were unable to give informed consent. Patients were randomized in a 1:1 fashion, to receive an ICD (ICD group) or usual care (control group).

Baseline data were collected concerning gender, age, BMI, blood pressure, smoking status, dialysis modality and dialysis vintage, cause of renal failure, and medication use. Additionally, information on cardiovascular comorbidity was documented.

\section{Questionnaires}

\section{MOS 36-item short-form health survey}

Patients were asked to fill out the validated Dutch language version of the Medical Outcome Study Questionnaire Short Form 36 Health Survey (SF-36, version 1) to assess healthrelated QOL at baseline, and at 1 year follow-up (Supplement 1) $[28,29]$. The SF-36 is a widely used measure of QOL and consists of eight subscales that are vitality, physical functioning, social functioning, bodily pain, general health perceptions, physical role functioning, emotional role functioning, and mental health. The SF-36 scores range from 0 to 100 . Higher scores indicate better QOL.

\section{Geriatric Depression Scale-15}

Among the respondents depression was assessed using a Dutch version of the Geriatric Depression Scale-15
(GDS-15, Supplement 2) [30]. Patients were asked to answer this mood scale which consists of 15 questions in a Yes/No format. Items 1, 5, 7, 11 and 13 answered with No corresponded with depression while all other items scored a point for depression if answered with Yes. GDS-15 scores of $0-5$ are in the normal range while a GDS scores of 6-10 are suggestive for mild depression and scores of 11 or greater are an indicator for major depression.

\section{Revised Life Orientation Test}

Optimism is a positive attitude about the future, otherwise described as one's tendency to expect positive outcomes. Dispositional optimism positively affects health outcomes and health-related behaviour, whilst the antonym pessimism is associated with negative outcomes such as hopelessness and depressive symptoms. The Revised Life Orientation Test (LOT-R) is a reliable and valid easy-to-use self-report measure to assess dispositional optimism [31]. Patients were assessed with the Dutch version of the LOT-R, which is a short 10-item Likert scale questionnaire which quantifies optimism (Supplement 3) [32]. Higher scores on the LOT-R correspond with higher levels of Optimism. Six out of 10 items of this questionnaire were analyzed; the remaining 4 items are distraction items, also known as fillers, and were excluded from statistical analyses. LOT-R items 1, 4 and 10 were related to Optimism, whilst items 3, 7 and 9 contributed to Pessimism.

\section{Health status: visual analogue scale}

On the visual analogue scale (VAS, Supplement 4) respondents were asked to choose a point on the straight line that corresponds to their state of health in the past week, where 0 is the worst health condition imaginable and 100 correlates with perfect health.

\section{Statistical analysis}

Statistical analyses were performed according to the perprotocol principle, using SPSS version 25.0 (IBM Corp, Armonk, New York, USA). Categorical data are presented as absolute numbers (\%) and continuous data as mean (SD), or median and interquartile range in case of a non-normal distribution. Analysis of each of the SF-36 domains was based on a simple (Welch) independent samples t-test, comparing changes in QOL outcomes between the two treatment arms. To compare mean LOT-R score differences (normally distributed data) between ICD and control group at the 2 time points, e.g. baseline and 1-year follow-up, an independent samples $t$ test was used. Using relative risk (RR) statistical differences were tested for occurrence of depression 
according to the GDS-15 questionnaire. Statistical significance was tested using the Chi-square test. Data regarding VAS was also analyzed using the independent samples $t$-test. We did not use imputation methods for missing data for the univariate analysis.

The internal consistency of the questionnaires was assessed using Cronbach's alpha. A Cronbach's alpha coefficient of $>0.7$ was considered evidence for scale reliability. Because both renal transplantation and repeated hospitalization can have an impact on QOL and psychological distress, a secondary analysis hierarchical multiple regression analysis was conducted, with change (from baseline to follow-up) in depression (GDS-15), Optimism (LOT-R) and QOL (the eight domains of the SF-36) as outcomes. Within each of the regression models, treatment arm was entered in block 1 . We have included the variables 'kidney transplant within 1 year following inclusion' and 'number of hospitalizations within 1 year following inclusion' in block 2 of the regression model. To control for baseline levels of the outcome variables, the baseline level of the outcome variable was entered in the third and final block of the regression model. A $p$ value below 0.05 was considered statistically significant.

Finally, as sensitivity analysis, to protect against possible missingness at random, we performed a linear mixed model analysis for each of the SF-36 domains, LOT-R and GDS-15, with time (categorical) and treatment and their interaction as fixed effects and with random person effects.

\section{Results}

\section{Descriptives and univariate analyses}

Between July 2007 and January 2018, a total of 188 patients were enrolled in the ICD2 trial, of which 97 in the ICD group and 91 in the control group [14]. Patients that refused ICD implantation or patients who could not receive an ICD implantation after being randomized to the treatment group were excluded from the per-protocol analysis $(n=17)$. So, 171 patients were included in the current per-protocol analysis, of which 80 patients were allocated to the ICD group and 91 patients to the standard care group (Fig. 1). The baseline characteristics are depicted in Table 1. Males represented $76.0 \%$ of our population. The median age was 67 years (interquartile range [IQR] 62-74). Haemodialysis was the predominant mode of renal replacement therapy (70.2\%). Table 1 also shows the baseline characteristics of the population with completed questionnaires at baseline and 1-year follow -up.

During 1-year follow-up, $7.0 \%$ (12 out of 171) of the patients underwent kidney transplantation, 7 out of 80 (8.8\%) in the ICD group and 5 out of $91(5.5 \%)$ in the control group (relative risk 0.6; 95\% CI 0.2-1.9; $p=0.41$, Table 2). In the same period, mortality rates were $6.3 \%$ (5 out of 80 ) in the ICD group and 4.4\% (4 out of 91) in the control group (relative risk $0.8 ; 95 \%$ CI $0.5-1.5 ; p=0.59$, Table 2 ). The most prevalent cause of death was of infectious origin. Among the 80 patients that underwent ICD implantation, 15
Fig. 1 Study flow chart. ICD indicates implantable cardioverter defibrillator. $L V E F$ left ventricular ejection fraction

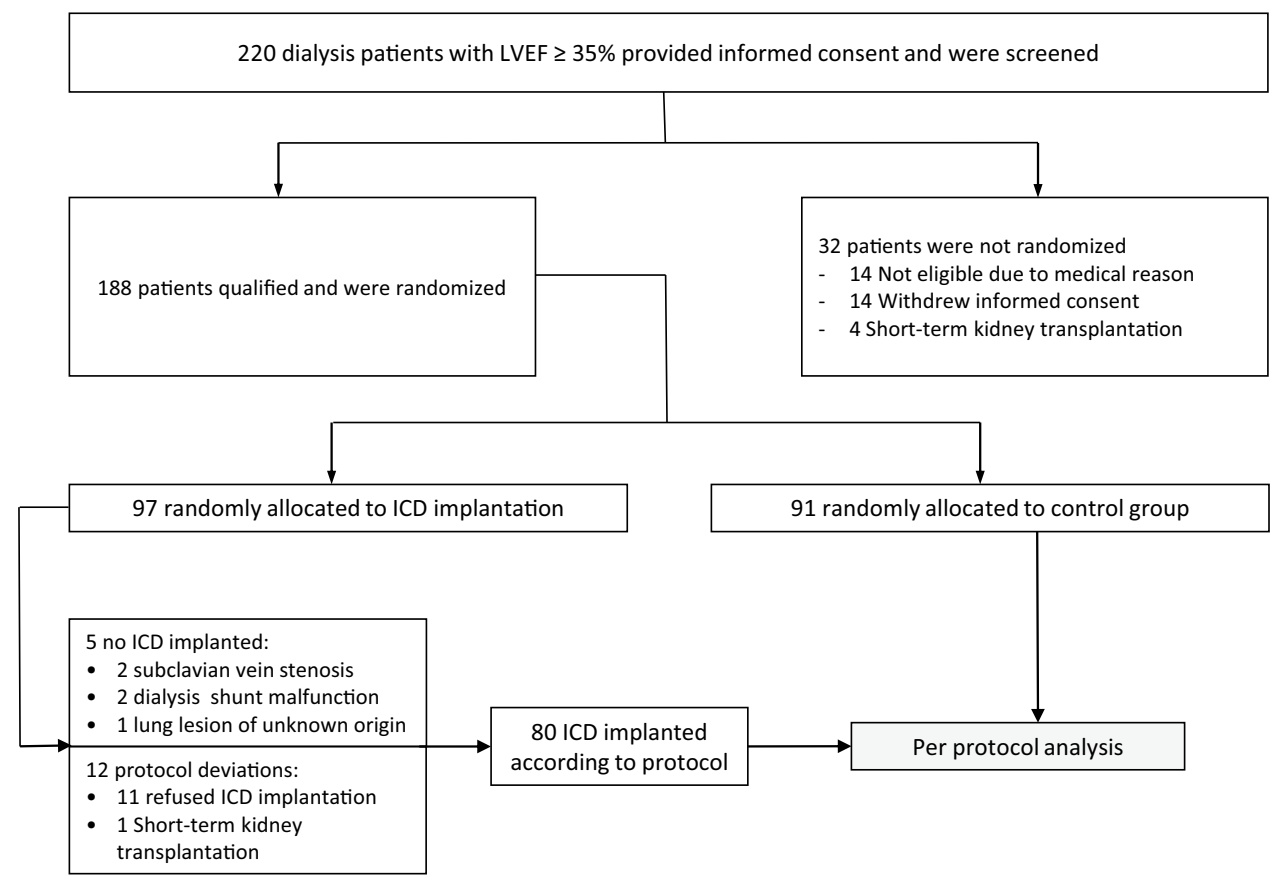


Table 1 Baseline characteristics

\begin{tabular}{|c|c|c|c|c|c|c|}
\hline & \multicolumn{3}{|c|}{ Per-protocol population } & \multicolumn{3}{|c|}{$\begin{array}{l}\text { Population with completed questionnaires } \\
\text { at baseline and } 1 \text { year follow-up* }\end{array}$} \\
\hline & $\begin{array}{l}\text { ICD Group } \\
(n=80)\end{array}$ & $\begin{array}{l}\text { Control Group } \\
(n=91)\end{array}$ & $p$ value & $\begin{array}{l}\text { ICD group } \\
(n=55)\end{array}$ & $\begin{array}{l}\text { Control Group } \\
(n=58)\end{array}$ & $p$ value \\
\hline Male, $n(\%)$ & $61(76.3)$ & $69(75.8)$ & 0.95 & $41(74.5)$ & $47(81.0)$ & 0.41 \\
\hline Age, years, median (IQR) & $67(63-74)$ & $68(61-74)$ & 0.68 & $67(63-75)$ & $67(60-74)$ & 0.90 \\
\hline Body mass index, $\mathrm{kg} / \mathrm{m}^{2}$, mean (SD) & $28.2(5.6)$ & $27.2(4.7)$ & 0.20 & $29.1(5.5)$ & $27.1(4.4)$ & 0.03 \\
\hline Heart rate, bpm, mean (SD) & $70(12)$ & $73(13)$ & 0.14 & $68(11)$ & $73(14)$ & 0.03 \\
\hline \multicolumn{7}{|l|}{ Blood pressure, mmHg, mean (SD) } \\
\hline Systolic & $141(23)$ & $138(21)$ & 0.46 & $139(21)$ & $138(23)$ & 0.73 \\
\hline Diastolic & $75(11)$ & $74(11)$ & 0.48 & $75(11)$ & $76(10)$ & 0.62 \\
\hline \multicolumn{7}{|l|}{ Dialysis } \\
\hline Duration of dialysis, months, median (IQR) & $16(9-24)$ & $15(10-27)$ & 0.95 & $16(8-22)$ & $15(10-29)$ & 0.91 \\
\hline Dialysis modality, $n(\%)$ & & & 0.77 & & & 0.67 \\
\hline Haemodialysis & $57(71.3)$ & $63(69.2)$ & & $39(70.9)$ & $39(67.2)$ & \\
\hline Peritoneal dialysis & $23(28.8)$ & $28(30.8)$ & & $16(29.1)$ & $19(32.8)$ & \\
\hline$K_{\mathrm{t}} / V$ urea/week & & & 0.48 & & & \\
\hline Haemodialysis, mean (SD) & $4.3(3.6-4.9)$ & $4.5(3.8-5.1)$ & & $4.3(1.0)$ & $4.5(0.9)$ & 0.45 \\
\hline Peritoneal dialysis, mean (SD) & $2.1(1.9-2.5)$ & $2.6(2.1-3.4)$ & & $2.1(0.5)$ & $3.0(0.7)$ & $<0.001$ \\
\hline \multicolumn{7}{|l|}{ Symptoms, $n(\%)$} \\
\hline Angina pectoris & $8(10.0)$ & $14(15.4)$ & 0.29 & $5(9.1)$ & $10(17.2)$ & 0.20 \\
\hline Palpitations & $17(21.3)$ & $21(23.1)$ & 0.77 & $11(20.0)$ & $14(24.1)$ & 0.60 \\
\hline Oedema & $7(8.8)$ & $12(13.2)$ & 0.36 & $4(7.3)$ & $8(13.8)$ & 0.26 \\
\hline Dyspnoea & $30(37.5)$ & $42(46.2)$ & 0.25 & $20(36.4)$ & $28(48.3)$ & 0.20 \\
\hline Orthopnoea & $7(8.8)$ & $5(5.5)$ & 0.41 & $5(9.1)$ & $3(5.2)$ & 0.48 \\
\hline Intermittent claudication & $15(18.8)$ & $14(15.4)$ & 0.56 & $9(16.4)$ & $7(12.1)$ & 0.51 \\
\hline \multicolumn{7}{|l|}{ Medical history, $n(\%)$} \\
\hline Diabetes mellitus & $27(33.8)$ & $38(41.8)$ & 0.28 & $20(36.4)$ & $21(36.2)$ & 0.99 \\
\hline Atrial fibrillation or flutter & $20(25.0)$ & $17(18.7)$ & 0.32 & $15(27.3)$ & $12(20.7)$ & 0.41 \\
\hline Percutaneous transluminal coronary angioplasty & $9(11.3)$ & $16(17.6)$ & 0.24 & $8(14.5)$ & $10(17.2)$ & 0.70 \\
\hline Coronary artery bypass graft & $8(10.0)$ & $13(14.3)$ & 0.39 & $4(7.3)$ & $6(10.3)$ & 0.57 \\
\hline Myocardial infarction & $16(20.0)$ & $27(29.7)$ & 0.15 & $12(21.8)$ & $17(29.3)$ & 0.36 \\
\hline Transient ischemic attack/cerebrovascular accident & $13(16.3)$ & $18(19.8)$ & 0.55 & $6(10.9)$ & $9(15.5)$ & 0.47 \\
\hline Hypertension & $66(82.5)$ & $71(78.0)$ & 0.46 & $45(81.8)$ & $47(81.0)$ & 0.92 \\
\hline Hypercholesterolemia & $45(56.3)$ & $43(47.3)$ & 0.24 & $32(58.2)$ & $29(50.0)$ & 0.38 \\
\hline \multicolumn{7}{|l|}{ Cardiovascular risk profile, $n(\%)$} \\
\hline Family history of premature cardiovascular disease & $28(35.0)$ & $30(33.0)$ & 0.78 & $18(32.7)$ & $21(36.2)$ & 0.70 \\
\hline Smoking, $n(\%)$ & & & 0.39 & & & 0.09 \\
\hline Never & $30(37.4)$ & $25(27.5)$ & & $23(41.8)$ & $14(24.1)$ & \\
\hline Yes & $17(21.3)$ & $26(28.6)$ & & $10(18.2)$ & $18(31.0)$ & \\
\hline In the past & $33(41.3)$ & $40(44.0)$ & & $22(40.0)$ & $26(44.8)$ & \\
\hline \multicolumn{7}{|l|}{ Medication use, $n(\%)$} \\
\hline Beta-blocker & $45(56.3)$ & $51(56.0)$ & 0.98 & $32(58.2)$ & $32(55.2)$ & 0.75 \\
\hline Angiotensin-converting enzyme inhibitor & $15(18.8)$ & $19(20.9)$ & 0.73 & $12(21.8)$ & $10(17.2)$ & 0.54 \\
\hline Angiotensin receptor blocker & $27(33.8)$ & $24(26.4)$ & 0.29 & $17(30.9)$ & $13(22.4)$ & 0.31 \\
\hline Calcium antagonist & $30(37.5)$ & $29(31.9)$ & 0.44 & $20(36.4)$ & $17(29.3)$ & 0.43 \\
\hline Statin & $47(58.8)$ & $58(63.7)$ & 0.50 & $35(63.6)$ & $38(65.5)$ & 0.83 \\
\hline Insulin & $14(17.5)$ & $20(22.0)$ & 0.46 & $10(18.2)$ & $11(19.0)$ & 0.92 \\
\hline Erythropoietin & $71(88.8)$ & $72(79.1)$ & 0.09 & $50(90.9)$ & $46(79.3)$ & 0.09 \\
\hline Cause of end-stage renal disease, $n(\%)$ & & & 0.30 & & & 0.08 \\
\hline Diabetic nephropathy & $20(25.0)$ & $21(23.1)$ & & $14(25.5)$ & $9(15.5)$ & \\
\hline
\end{tabular}


Table 1 (continued)

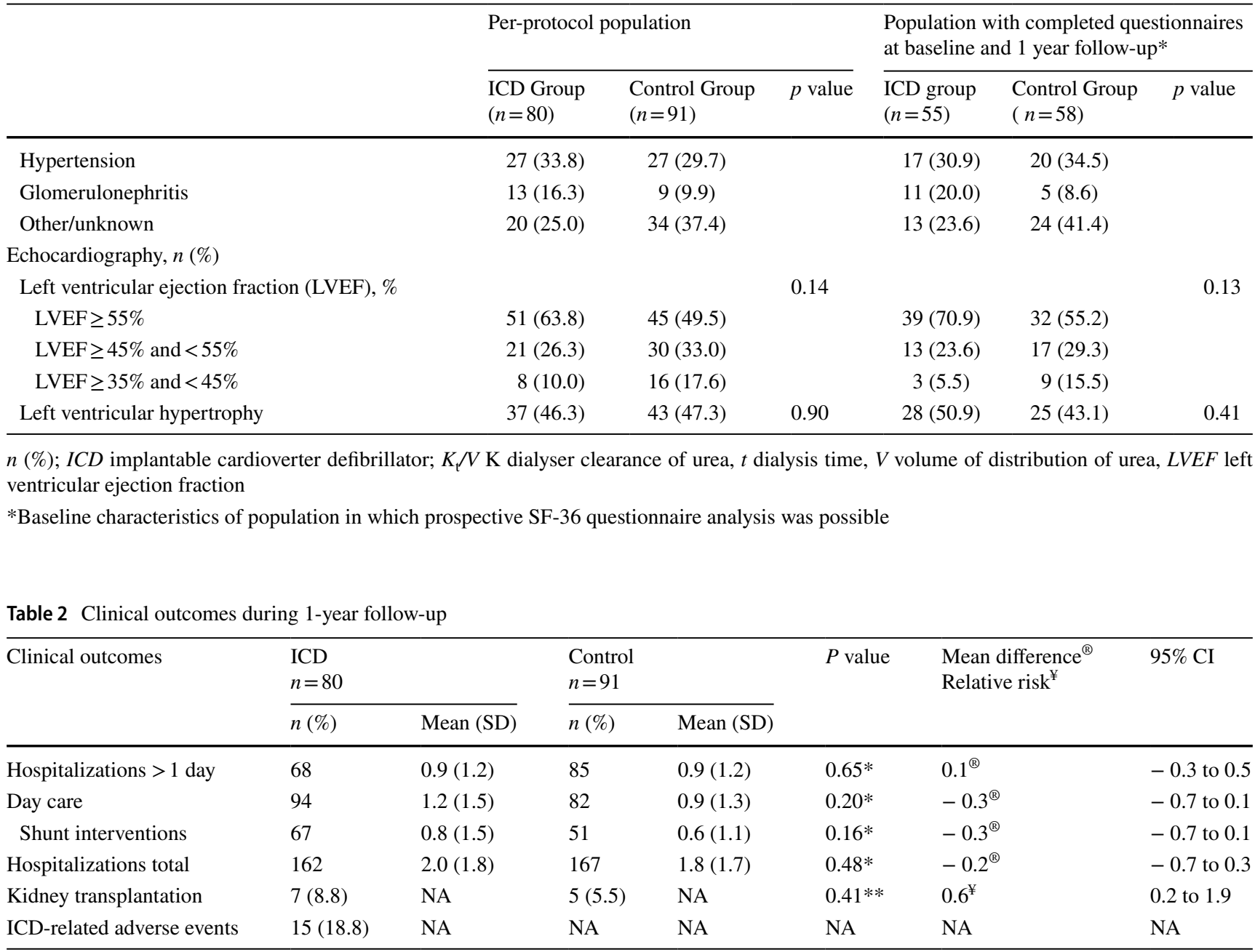

$C I$ confidence interval, ICD implantable cardioverter defibrillator, $N$ number, $N A$ not applicable, $S D$ standard deviation

*Unpaired $t$ test, ${ }^{* *} \mathrm{Chi}^{2}$ test, ${ }^{\circledR}$ Mean difference, ${ }^{\mathrm{q}}$ Relative risk

ICD-related adverse events occurred during 1-year followup. These adverse events were lead dysfunction/dislocation $(n=5)$, pocket infection $(n=4)$, pocket haematoma $(n=2)$, central venous stenosis $(n=2)$, lead perforation $(n=1)$ and inappropriate shock $(n=1)$. None of the patients in the ICD group received defibrillation therapy during 1-year follow-up.

\section{Questionnaire analyses}

The Cronbach's coefficient alpha estimates for the questionnaires are presented in Table 3. The internal consistency reliability of all scales exceeded 0.70 , with the exception of the LOT-R.

The response rates and results of the SF-36, GDS-15, VAS and LOT-R questionnaires are shown in Table 4. As expected, the mean scores of all SF-36 subcategories of patients randomized to receive an ICD and patients randomized for standard care, were similar at baseline (Fig. 2, Table 4). The changes in QOL outcomes regarding all SF-36 outcome variables, e.g. mean scores after a time interval of 1 year (T1) minus the baseline mean scores (T0), in the ICD group were statistically nonsignificant compared with changes in QOL outcomes in the control group (physical functioning ( $p=0.43)$, social functioning $(p=0.89)$, physical role functioning $(p=0.49)$, emotional role functioning $(p=0.84)$, mental health $(p=0.91)$, vitality $(p=0.12)$, bodily pain $(p=0.61)$, general health perceptions $(p=0.85)$, health change $(p=0.50)$ and health status $(p=0.97))$. The GDS-15 score difference (GDS-15 score at T1 minus GDS15 score at T0) was 0.5 (2.1) in the ICD group compared with $0.3(2.2)$ in the control group (mean difference -0.3 (2.2); 95\% CI -1.1 to 0.6 ; $p=0.58$ ). The LOT-R score difference (LOT-R score at $\mathrm{T} 1$ minus LOT-R score at T0) was 
Table 3 Internal consistency reliability

\begin{tabular}{|c|c|c|c|}
\hline \multirow[t]{2}{*}{ Scale } & \multirow{2}{*}{$\begin{array}{l}\text { Number } \\
\text { of items }\end{array}$} & \multicolumn{2}{|l|}{ Cronbach's alpha } \\
\hline & & Baseline & Follow-up \\
\hline \multicolumn{4}{|l|}{ SF-36 Item } \\
\hline 1. Physical function & 10 & 0.92 & 0.75 \\
\hline 2. Role physical & 4 & 0.88 & 0.91 \\
\hline 3. Bodily pain & 2 & 0.80 & 0.88 \\
\hline 4. General health & 5 & 0.74 & 0.72 \\
\hline 5. Vitality & 4 & 0.73 & 0.85 \\
\hline 6. Social functioning & 2 & 0.73 & 0.80 \\
\hline 7. Role emotional & 3 & 0.85 & 0.87 \\
\hline 8. Mental health & 5 & 0.78 & 0.72 \\
\hline 9. Health change & 1 & Not applicable & Not applicable \\
\hline \multicolumn{4}{|l|}{$\begin{array}{l}\text { Life Orientation Test- } \\
\text { Revised }\end{array}$} \\
\hline Optimism & $3^{\mathrm{a}}$ & 0.50 & 0.53 \\
\hline Pessimism & $3^{\mathrm{b}}$ & 0.71 & 0.61 \\
\hline \multicolumn{4}{|l|}{$\begin{array}{l}\text { Geriatric Depression } \\
\text { Scale-15 }\end{array}$} \\
\hline & 15 & 0.83 & 0.80 \\
\hline
\end{tabular}

*LOT-R items 1, 4 and 10 are positively warded

${ }^{\dagger}$ LOT-R items 3, 7 and 9 are negatively warded

$-0.2(4.1)$ in the ICD group compared with $-1.5(4.0)$ in the control group (mean difference - $1.1(0.8) ; 95 \% \mathrm{CI}-2.6$ to $0.4 ; p=0.17$ ). The VAS score difference (VAS score at T1 minus VAS score at T0) was - 1.3 (19.7) in the ICD group compared with -1.5 (21.8) in the control group (mean difference $0.2 ; 95 \% \mathrm{CI}-7.8$ to $8.2 ; p=0.97)$.

\section{Regression analyses}

The results of the regression analyses are reported in Table 5. For Depression, the total variance explained by the final model (including all three blocks) was $3.5 \%$. The only variable that significantly contributed to changes in depression from baseline to follow-up, was having a kidney transplantation during the 1-year follow-up period $(\mathrm{p}=0.047)$, with patients who had a transplantation reporting less depression at follow-up. For Optimism, the total variance explained by the final model was $37.6 \%$. The only significant predictor was baseline level of Optimism $(p<0.001)$. For the Vitality subscale of the SF-36, the total variance explained by the final model was $14 \%$. Two variables significantly predicted changes in vitality from baseline to follow-up. The strongest predictor was Vitality at baseline $(p<0.001)$, followed by having a transplantation during the follow-up period, with patients who had a transplantation reporting higher levels of Vitality at follow-up $(p=0.02)$. For Physical Functioning, Social Functioning, Physical Role Functioning, Emotional Role Functioning, Mental Health, and Bodily Pain, the total variance explained by the final model was $6 \%, 14 \%, 18 \%, 30 \%, 22 \%$, and $7.3 \%$, respectively. For each of these outcomes, the baseline level of the outcome was the only significant predictor of changes from baseline to follow-up ( $p=0.01, p=0.001, p=0.001$, $p<0.001, p<0.001$, and $p=0.001$, respectively). Finally, the final model explained $25.1 \%$ of the variance with respect to changes in perceived General Health from baseline to follow up. Both General Health Perception at baseline $(p<0.001)$ and receiving a kidney transplantation during the follow-up period ( $p=0.001)$ significantly predicted the outcome, with patients receiving a transplantation reporting better General Health at 1-year follow-up.

\section{Sensitivity analysis}

The main purpose of this sensitivity analysis was to check whether the results of differences in changes in QOL outcomes between the two treatment arms in the simple t-test coincided with that of the interaction in the linear mixed model. For all QOL outcomes the differences in changes in QOL outcomes between the treatment arms were both quantitatively (in terms of effect sizes) and quantitatively (in terms of statistical significance) similar (eSupplement 1, SPSS output).

\section{Discussion}

Previously we reported on the quantitative data of the impact of ICD therapy in patients undergoing dialysis, with respect to survival and adverse effects, by executing a randomized clinical trial [14]. In this paper, we report on the longitudinal assessment of the physical and mental disease burden of ICD-recipients on dialysis $(n=80)$ versus patients undergoing dialysis without an ICD $(n=91)$, using three validated self-report questionnaires. In this per-protocol subanalysis of the ICD2 trial we found that in ESRD patients undergoing dialysis, ICD implantation did not (negatively or positively) affect QOL, mood or dispositional optimism in the first year post-implantation. Multiple regression analysis showed that a kidney transplantation during the 1-year follow-up period significantly contributed to changes in depression from baseline to follow-up $(p=0.047)$, with patients who had a transplantation reporting less depression at follow-up. Additionally, patients receiving a transplantation reported better General Health at 1-year follow-up.

To the best of our knowledge, we are the first to report on the impact of an ICD on QOL in this population. Early recognition (of patients at high risk) of adverse psychological events is of paramount importance for timely intervention. In comparison with other reports of QOL in ICD-recipients or reports of QOL among patients on dialysis, our trial consists 
Table 4 Scores of the SF-36, health status, GDS-15 and the LOT-R

\begin{tabular}{|c|c|c|c|c|c|c|c|c|c|}
\hline \multirow[t]{2}{*}{$\begin{array}{l}\text { Questionnaire } \\
\text { Scores }\end{array}$} & \multicolumn{3}{|l|}{$\begin{array}{l}\text { ICD group } \\
(n=80)\end{array}$} & \multicolumn{3}{|l|}{$\begin{array}{l}\text { Control group } \\
(n=91)\end{array}$} & \multirow[t]{2}{*}{$\begin{array}{l}\text { Mean differ- } \\
\text { ence* }\end{array}$} & \multirow[t]{2}{*}{$\Delta 95 \% \mathrm{CI}$} & \multirow[t]{2}{*}{$p^{\dagger}$} \\
\hline & $\begin{array}{l}\text { Score at base- } \\
\text { line (T0) }\end{array}$ & $\begin{array}{l}\text { Scores at } \\
12 \text { months } \\
(T 1)\end{array}$ & $\Delta \mathrm{T} 1-\mathrm{T} 0$ & $\begin{array}{l}\text { Score at base- } \\
\text { line (T0) }\end{array}$ & $\begin{array}{l}\text { Scores at } \\
12 \text { months } \\
\text { (T1) }\end{array}$ & $\Delta \mathrm{T} 1-\mathrm{T} 0$ & & & \\
\hline \multicolumn{10}{|l|}{$\begin{array}{l}\text { SF-36 scores, } \\
\text { mean (SD) }\end{array}$} \\
\hline $\begin{array}{l}\text { Response rate, } \\
n(\%)\end{array}$ & $72(90.0)$ & $62(77.5)$ & NA & $82(90.1)$ & $61(67.0)$ & NA & NA & NA & NA \\
\hline $\begin{array}{l}\text { Physical func- } \\
\text { tioning }\end{array}$ & $56.5(27.3)$ & $52.8(38.0)$ & $-3.7(29.8)$ & $60.8(26.4)$ & $53.3(25.4)$ & $-7.6(20.2)$ & 3.9 & -5.9 to 13.7 & 0.43 \\
\hline $\begin{array}{l}\text { Social func- } \\
\text { tioning }\end{array}$ & $73.0(22.5)$ & $71.8(28.1)$ & $-1.1(27.0)$ & $73.5(21.3)$ & $73.0(26.2)$ & $-0.4(27.8)$ & -0.7 & -11.0 to 9.6 & 0.89 \\
\hline $\begin{array}{r}\text { Physical role } \\
\text { limitations }\end{array}$ & $47.0(43.6)$ & $52.5(47.4)$ & $5.5(45.5)$ & $34.7(41.0)$ & $34.7(40.8)$ & $0(34.3)$ & 5.5 & - 10.3 to 21.3 & 0.49 \\
\hline $\begin{array}{c}\text { Emotional role } \\
\text { limitations }\end{array}$ & $71.4(42.5)$ & $72.1(42.1)$ & $0.7(48.3)$ & $67.9(40.8)$ & $66.7(40.8)$ & $-1.2(46.7)$ & 1.9 & - 16.8 to 20.6 & 0.84 \\
\hline Mental health & $79.2(15.1)$ & $77.5(16.5)$ & $-1.7(17.3)$ & 79.9 (15.7) & 78.5 (15.6) & $-1.4(14.7)$ & -0.3 & -5.7 to 6.4 & 0.91 \\
\hline Vitality & $57.9(19.4)$ & $57.6(23.2)$ & $-0.3(20.6)$ & $56.7(17.5)$ & $50.5(20.7)$ & $-6.1(18.4)$ & 5.9 & -1.5 to 13.2 & 0.12 \\
\hline Bodily pain & $75.1(23.0)$ & $70.6(31.0)$ & $-4.4(27.5)$ & $74.3(21.7)$ & $72.3(25.2)$ & $-2.0(23.6)$ & -2.5 & -12.1 to 7.2 & 0.61 \\
\hline $\begin{array}{l}\text { General health } \\
\text { perceptions }\end{array}$ & $42.3(17.0)$ & $41.3(16.4)$ & $-1.1(15.0)$ & $42.4(18.2)$ & 41.9 (19.6) & $-0.4(18.5)$ & -0.6 & -7.0 to 5.8 & 0.85 \\
\hline Health change & $60.5(29.1)$ & $54.5(24.6)$ & $-5.9(33.0)$ & $58.3(27.7)$ & $48.2(24.0)$ & $-10.1(32.3)$ & 4.2 & -8.1 to 16.4 & 0.50 \\
\hline $\begin{array}{l}\text { Health status } \\
\text { (VAS), mean } \\
\text { (SD) }\end{array}$ & $62.6(19.3)$ & $61.3(20.5)$ & $-1.3(19.7)$ & $65.1(19.3)$ & $63.6(20.6)$ & $-1.5(21.8)$ & 0.2 & -7.8 to 8.2 & 0.97 \\
\hline $\begin{array}{l}\text { Response rate, } \\
n(\%)\end{array}$ & $70(87.5)$ & $61(76.3)$ & NA & 77 (84.6) & $62(68.1)$ & NA & NA & NA & NA \\
\hline $\begin{array}{l}\text { GDS-15 Score } \neq \\
\text { mean }(\mathrm{SD})\end{array}$ & $2.9(2.8)$ & $3.0(2.7)$ & $0.5(2.1)$ & $3.2(3.1)$ & $3.1(2.9)$ & $0.3(2.2)$ & -0.3 & -1.1 to 0.6 & 0.58 \\
\hline Response rate & $63(78.8)$ & $61(76.3)$ & NA & $71(78.0)$ & $61(67.0)$ & NA & NA & NA & NA \\
\hline $\begin{array}{l}\text { No depression, } \\
n(\%)\end{array}$ & $54(67.5)$ & $54(67.5)$ & NA & $58(63.7)$ & $53(58.2)$ & NA & NA & NA & NA \\
\hline $\begin{array}{l}\text { Mild depres- } \\
\text { sion, } n(\%)\end{array}$ & $7(8.8)$ & $5(6.3)$ & NA & $9(9.9)$ & $6(6.6)$ & NA & NA & NA & NA \\
\hline $\begin{array}{l}\text { Major depres- } \\
\text { sion, }(\%)\end{array}$ & $2(2.5)$ & $2(2.5)$ & NA & $4(4.5)$ & $2(2.2)$ & NA & NA & NA & NA \\
\hline $\begin{array}{l}\text { LOT-R score }^{\S} \\
\text { mean }(\mathrm{SD})\end{array}$ & $14.6(3.4)$ & $14.6(3.0)$ & $-0.2(4.1)$ & $14.8(3.3)$ & $13.6(3.1)$ & $-1.5(4.0)$ & $-1.1(0.8)$ & -2.6 to 0.4 & 0.17 \\
\hline $\begin{array}{l}\text { Response rate, } \\
n(\%)\end{array}$ & $61(76.3)$ & $61(76.3)$ & NA & $71(78.0)$ & $60(65.9)$ & NA & NA & NA & NA \\
\hline
\end{tabular}

$T 0$ score at baseline (prior to potential ICD implantation), mean (SD), $T 1$ score at 1-year follow-up, mean (SD), $\Delta T 1-T 0$ score difference, mean (SD); $\Delta 95 \%$ CI 95\% confidence interval of score difference, $n$ number, $N A$ not applicable, $S D$ standard deviation, $S F-36$ Medical Outcome Study Questionnaire Short Form 36 Health Survey, GDS-15 Geriatric Depression Scale-15, LOT-R Revised Life Orientation Test, VAS visual analogue scale

$*$ Mean difference $=\Delta \mathrm{T} 1-\mathrm{T} 0 \mathrm{ICD}$ group minus $\Delta \mathrm{T} 1-\mathrm{T} 0$ control group

${ }^{\dagger}$ Welch two sample $t$ test of $\Delta \mathrm{T} 1-\mathrm{T} 0$ control group versus $\Delta \mathrm{T} 1-\mathrm{T} 0 \mathrm{ICD}$ group

${ }^{\ddagger}$ No Depression was defined as a GDS score of 0 to 5. Mild Depression was defined as a GDS score of 6 to 10. Major Depression was defined as a GDS score of 10 to 15

${ }^{\S}$ On the LOT-R scale from 0 to 24 , patients with low scores are considered pessimists, whilst patients with high scores are deemed optimists. There are no cut-off points on the pessimism-optimism continuum

of a relatively large population $(n=188)[21,22]$. Also, the follow-up duration of the current study of 12 months offers valuable insights. Moreover, our trial design included a proper control group. Also, we assessed the preimplantation scores of the three questionnaires, which is an important strength of this trial. Reliable and valid screening devices 
A

Baseline (T0)

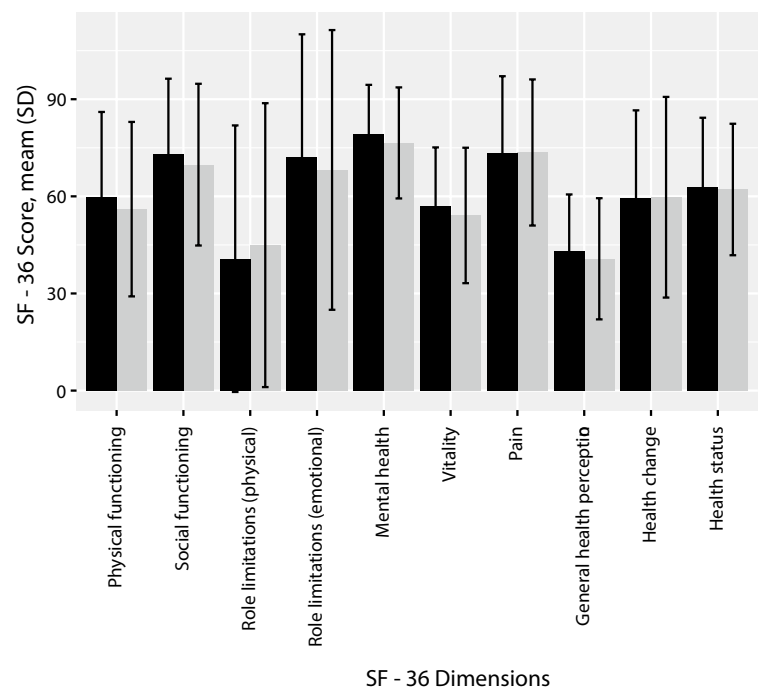

B

1 year follow-up (T1)

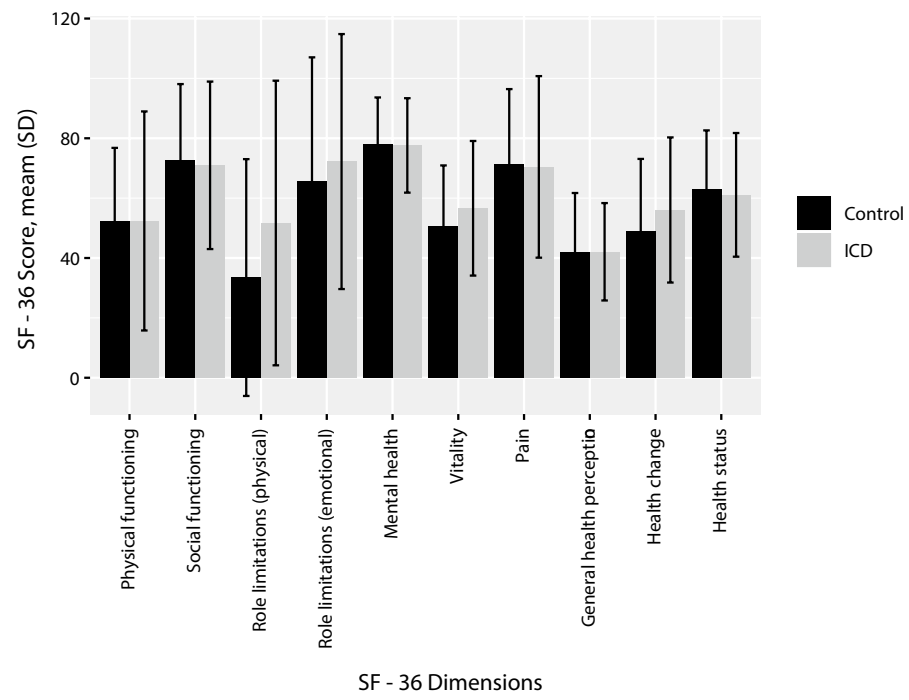

Fig. 2 a SF-36, Baseline comparison of ICD group versus Control group. b SF-36, Follow-up comparison of ICD group versus Control group. $\mathrm{T} 0=$ mean $(\mathrm{SD})$ scores at baseline, prior to potential ICD implantation; $\mathrm{T} 1=$ mean $(\mathrm{SD})$ scores at 1 -year follow-up

were used for measuring mental well-being and certain traits that influence coping behaviour. The fact that we have not been able to demonstrate an effect of ICD implantation on the mentioned scales does not seem to be based on an underpowerment of this study. As we are the first to perform a prospective evaluation of the effect of ICD therapy on the physical and mental state of patients with ESRD we cannot compare our results with other reports from the literature.

Multiple studies evaluating QOL in patients on dialysis report high rates of depression and anxiety [6, 7, 33]. Kim et al. assessed QOL among hemodialysis patient and found similar health-related QOL scores compared to our results [33]. Also, Nagasawa and colleagues evaluated the effect of QOL on medication compliance among 92 dialysis patients and found QOL-scores comparable to QOL-scores in this report [7]. Adaptation distress among ICD-recipients in the general population has also been described in several reports [11, 23]. However, these reports mostly concern cross-sectional data, or longitudinal data with small sample size, and are lacking a proper control group without an ICD. Also, consensus regarding the relationship of QOL and ICD implantation is lacking because of equivocal trial outcomes [11, 21-23, 34]. Kamphuis et al. assessed QOL and depressive symptoms in a 12-month longitudinal study among 132 ICD-recipients versus 35 patients without ICD and found clinically significant depressive symptoms in $22-66 \%$ of ICD recipients throughout the first year [21]. Lewin et al. conducted an RCT to assess the effect of cognitive behavioural rehabilitation on QOL and depression in 192 patients scheduled to receive an ICD and after 6 months following ICD-implantation [35]. However, this study group did not include a control group that did not undergo ICD-implantation. Also, both randomization groups were not comparable with regard to baseline QOL and depression scores [35]. Friedman et al. mapped the QOL and anxiety among 48 ICD recipients in a cross-sectional study and found that younger patients were at the highest risk of psychological distress and poor QOL [22]. Irvine et al. performed a randomized controlled trial to assess the impact of ICD implantation on QOL among 317 patients known with sustained ventricular arrhythmias randomized to receive ICD implantation $(n=157)$ or amiodarone $(n=160)$. Authors found, after a follow-up of 12 months, that QOL improved in the ICD group [36]. Conversely, Schron et al. compared QOL outcomes among 416 patients randomized for ICD implantation versus 384 patients receiving anti-arrhythmic drugs and found no significant difference over 1-year follow-up [37]. Magyar-Russel et al. reviewed 42 studies that assessed (symptoms of) depression among ICD recipients, of which only 5 were longitudinal cohort reports, all suggesting no change over time [11]. Fitchet et al. performed an RCT among 12 ICD recipients and found 12 week cardiac rehabilitation can improve anxiety and depression rates [38]. Sears et al. performed an RCT to assess the effect of psychological treatment on depression and QOL among 30 ICD-recipients that received an ICD-shock within 1 year following device implantation. The investigators found that depression, and QOL improved significantly from baseline 


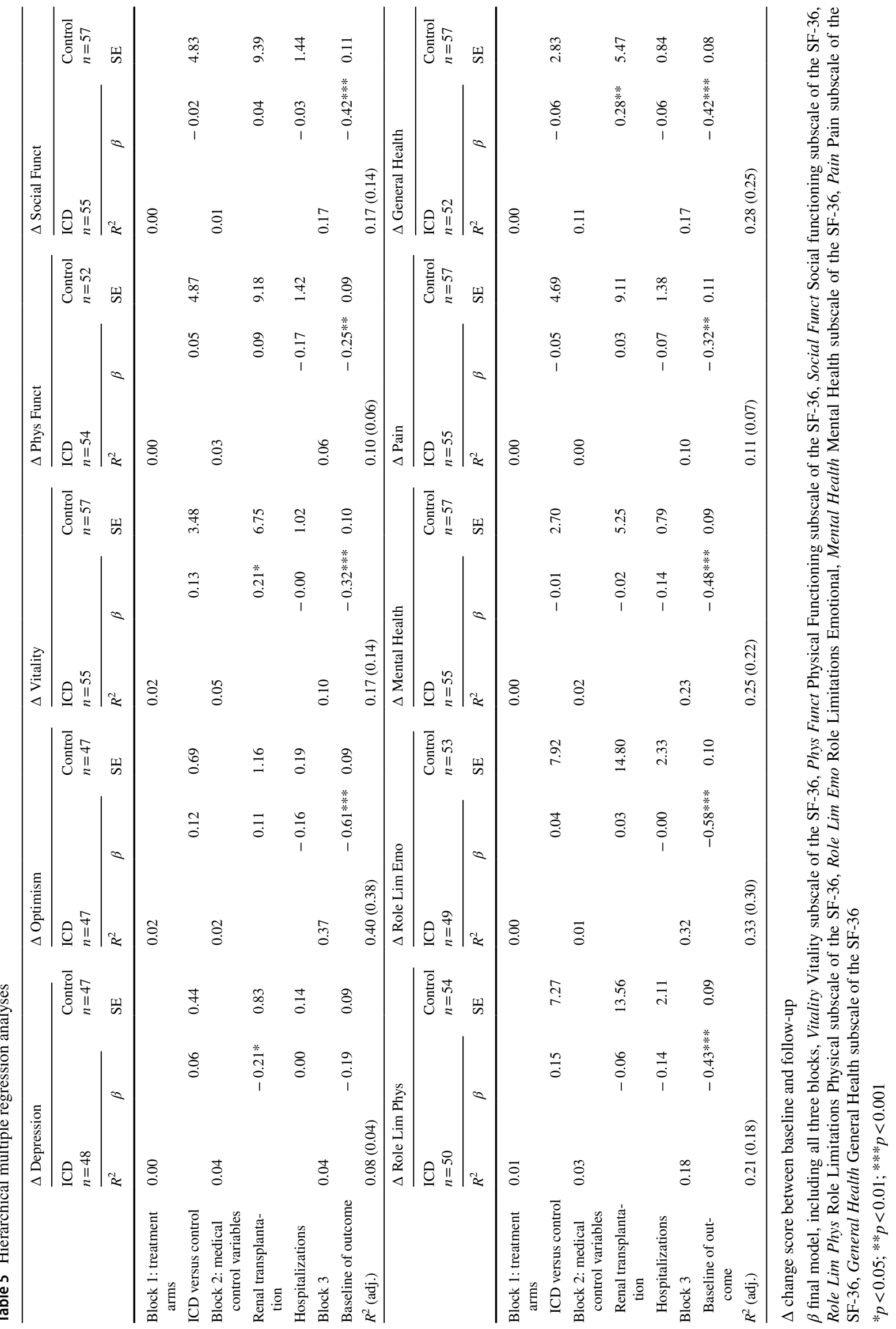


to postintervention in all participants and concluded that structured interventions for shocked ICD patients involving ICD education and cognitive-behavioural strategies can reduce psychological distress and improve QOL [20].

Our trial had some limitations. Firstly, as in any trial, we had patients from the main trial that did not want to participate in this substudy. The baseline characteristics of the subgroup with completed questionnaires at baseline and 1-year follow-up are depicted in Table 1, in addition to the baseline characteristics of the complete per protocol population. This table shows that both populations are very similar, as expected. Secondly, although the LOT-R is a widely used, and well-validated questionnaire to measure dispositional Optimism, we found a low internal validity in our population, especially for the subscale measuring Optimism. As can be seen in Table 3 the Cronbach's alphas for Optimism ( $\alpha=0.50$ at baseline, $\alpha=0.53$ at follow up) and Pessimism at follow up $(\alpha=0.61)$ yielded a lower internal consistency than expected. One explanation for this is the limited number of items the subscales consist of. An additional explanation for the low internal consistency of the subscale Optimism, both at baseline and at follow-up, is the fact that the intercorrelations between the items the subscale consists of are quite low. Thirdly, absence of significant findings may be the result of the limited sample size. However, with respect to reports in literature, our population is relatively large and has a control group. Also, we performed a sensitivity analysis and found that for all QOL outcomes the differences in changes in QOL outcomes between the treatment arms were both quantitatively (in terms of effect sizes) and quantitatively (in terms of statistical significance) similar. Furthermore, our population consisted of a highly selective patient group. Consequently, results may not be generalizable to the overall dialysis/ICD population. However, we found approximately equal levels of QOL in our dialysis population compared with reports in the literature [5, 24, 33]. Also, we did not include patients with a class I indication for ICD implantation according to the current guidelines. The long-term effect of ICD implantation in dialysis patients has not been charted, as follow up in our trial was performed following a time span of 1 year. The poor prognosis of this vulnerable patient group would lead to high rate of missing values because of high mortality in case of longer follow-up. Furthermore, prospective collection of multiple extensive questionnaires can be experienced as bothersome by patients, which does not benefit the response rate. However, distress levels may change over time. It could be hypothesized that after longer follow up an ICD could provide feelings of safety and results in a better QOL due to less anxiety through better adaptation. Conversely, feelings of anxiety for imminent shock and occurrence of adverse events, could lead to a further decrease in QOL after longer follow-up. We did not map the social support of patients.
In conclusion, in the current trial we shed light on the physical and psychological well-being of ESRD patients on dialysis undergoing prophylactic ICD implantation for primary prevention. Our data suggests that ICD implantation does not seem to influence QOL, negatively or positively, among dialysis patients during 1-year follow-up. Based on these results, we believe that our study provides evidence that in case of a hard indication for preventive ICD implantation, this procedure should not be withheld in this population. Further study is warranted for evaluation of long-term implication of an ICD in this vulnerable patient group.

Supplementary Information The online version of this article (https:// doi.org/10.1007/s11136-020-02744-7) contains supplementary material, which is available to authorised users.

Author contributions Drs Timal and Jukema had full access to all of the data in the study and take responsibility for the integrity of the data and the accuracy of the data analysis. Study concept and design: Rotmans, Putter, Schalij, Rabelink, Jukema. Drafting of the manuscript: Timal. Acquisition, analysis, or interpretation of data: Timal, de Gucht, Hensen, Buiten, de Bie, Rotmans, Putter, Schalij, Rabelink, Jukema. Critical revision of the manuscript for important intellectual content: de Gucht, Hensen, Buiten, de Bie, Rotmans, Putter, Schalij, Rabelink, Jukema. Statistical analysis: Timal, de Gucht, Putter. Obtained funding: Schalij, Rabelink, Jukema. Study supervision: Schalij, Rabelink, Jukema.

Funding The ICD2 trial was supported by an unrestricted educational research grant from Biotronik $\mathrm{GmbH} \& \mathrm{Co}$. The study sponsors had no role in the study design or in the collection, analysis, and interpretation of data, the writing of the report, or the decision to submit the paper for publication.

Data availability The data that support the findings of this study are available from the corresponding author upon reasonable request. Code availability The SPSS syntaxes used for the analysis of this study are available from the corresponding author upon reasonable request.

\section{Compliance with ethical standards}

Conflict of interest The authors declared that they have no conflict of interest.

Open Access This article is licensed under a Creative Commons Attribution 4.0 International License, which permits use, sharing, adaptation, distribution and reproduction in any medium or format, as long as you give appropriate credit to the original author(s) and the source, provide a link to the Creative Commons licence, and indicate if changes were made. The images or other third party material in this article are included in the article's Creative Commons licence, unless indicated otherwise in a credit line to the material. If material is not included in the article's Creative Commons licence and your intended use is not permitted by statutory regulation or exceeds the permitted use, you will need to obtain permission directly from the copyright holder. To view a copy of this licence, visit http://creativecommons.org/licenses/by/4.0/. 


\section{References}

1. United States Renal Data System Annual Data Report. (2018). Epidemiology of kidney disease in the United States. Bethesda, MD: National Institutes of Health, National Institute of Diabetes and Digestive and Kidney Diseases.

2. Reszke, R., \& Szepietowski, J. C. (2018). End-stage renal disease chronic itch and its management. Dermatologic Clinics, 36(3), 277-292. https://doi.org/10.1016/j.det.2018.02.007.

3. Gerogianni, G., Babatsikou, F., Polikandrioti, M., \& Grapsa, E. (2019). Management of anxiety and depression in haemodialysis patients: The role of non-pharmacological methods. International Urology and Nephrology, 51(1), 113-118. https://doi.org/10.1007/ s11255-018-2022-7.

4. Ramakrishnan, K., Bond, T. C., Claxton, A., Sood, V. C., Kootsikas, M., Agnese, W., et al. (2013). Clinical characteristics and outcomes of end-stage renal disease patients with self-reported pruritus symptoms. International Journal of Nephrology and Renovascular Disease, 7, 1-12. https://doi.org/10.2147/ijnrd.S52985.

5. Susel, J., Batycka-Baran, A., Reich, A., \& Szepietowski, J. C. (2014). Uraemic pruritus markedly affects the quality of life and depressive symptoms in haemodialysis patients with end-stage renal disease. Acta Dermato Venereologica, 94(3), 276-281. https ://doi.org/10.2340/00015555-1749.

6. Krespi, M. R. (2018). Psychosocial interventions to improve outcomes among dialysis patients. Seminars in Dialysis, 31(1), 65-71. https://doi.org/10.1111/sdi.12638.

7. Nagasawa, H., Tachi, T., Sugita, I., Esaki, H., Yoshida, A., Kanematsu, Y., et al. (2018). The effect of quality of life on medication compliance among dialysis patients. Frontiers in Pharmacology, 9, 488. https://doi.org/10.3389/fphar.2018.00488.

8. Natale, P., Palmer, S. C., Ruospo, M., Saglimbene, V. M., Rabindranath, K. S., \& Strippoli, G. F. (2019). Psychosocial interventions for preventing and treating depression in dialysis patients. Cochrane Database of Systematic Reviews, 12, CD004542. https ://doi.org/10.1002/14651858.CD004542.pub3.

9. Picariello, F., Moss-Morris, R., Macdougall, I. C., \& Chilcot, A. J. (2017). The role of psychological factors in fatigue among endstage kidney disease patients: A critical review. Clinical Kidney Journal, 10(1), 79-88. https://doi.org/10.1093/ckj/sfw113.

10. Dabrowska-Bender, M., Dykowska, G., Zuk, W., Milewska, M., \& Staniszewska, A. (2018). The impact on quality of life of dialysis patients with renal insufficiency. Patient Prefer Adherence, 12, 577-583. https://doi.org/10.2147/ppa.S156356.

11. Magyar-Russell, G., Thombs, B. D., Cai, J. X., Baveja, T., Kuhl, E. A., Singh, P. P., et al. (2011). The prevalence of anxiety and depression in adults with implantable cardioverter defibrillators: A systematic review. Journal of Psychosomatic Research, 71(4), 223-231. https://doi.org/10.1016/j.jpsychores.2011.02.014.

12. van der Borg, W. E., Verdonk, P., de Jong-Camerik, J. G., Schipper, K., \& Abma, T. A. (2019). A continuous juggle of invisible forces: How fatigued dialysis patients manage daily life. Journal of Health Psychology. https://doi.org/10.1177/135910531985334 0 .

13. USRDS. (2006). ADR: Morbidity \& Mortality (2007). American Journal of Kidney Diseases, 49, S129-S146. https://doi. org/10.1053/j.ajkd.2006.11.011.

14. Jukema, J. W., Timal, R. J., Rotmans, J. I., Hensen, L. C. R., Buiten, M. S., de Bie, M. K., et al. (2019). Prophylactic use of implantable cardioverter-defibrillators in the prevention of sudden cardiac death in dialysis patients. Circulation, 139(23), 26282638. https://doi.org/10.1161/circulationaha.119.039818.

15. Antiarrhythmics versus Implantable Defibrillators (AVID) Investigators. (1997). A comparison of antiarrhythmic-drug therapy with implantable defibrillators in patients resuscitated from near-fatal ventricular arrhythmias. The New England Journal of Medicine, 337(22), 1576-1583. https://doi.org/10.1056/nejm19971127337 2202.

16. Bardy, G. H., Lee, K. L., Mark, D. B., Poole, J. E., Packer, D. L., Boineau, R., et al. (2005). Amiodarone or an implantable cardioverter-defibrillator for congestive heart failure. New England Journal of Medicine, 352(3), 225-237. https://doi.org/10.1056/ NEJMoa043399.

17. Moss, A. J., Hall, W. J., Cannom, D. S., Daubert, J. P., Higgins, S. L., Klein, H., et al. (1996). Improved survival with an implanted defibrillator in patients with coronary disease at high risk for ventricular arrhythmia. Multicenter Automatic Defibrillator Implantation Trial Investigators. The New England Journal of Medicine, 335(26), 1933-1940. https://doi.org/10.1056/nejm19961226335 2601.

18. Moss, A. J., Zareba, W., Hall, W. J., Klein, H., Wilber, D. J., Cannom, D. S., et al. (2002). Prophylactic implantation of a defibrillator in patients with myocardial infarction and reduced ejection fraction. New England Journal of Medicine, 346(12), 877-883. https://doi.org/10.1056/NEJMoa013474.

19. Van Den Broek, K. C., Habibovic, M., \& Pedersen, S. S. (2010). Emotional distress in partners of patients with an implantable cardioverter defibrillator: A systematic review and recommendations for future research. Pacing and Clinical Electrophysiology, 33(12), 1442-1450. https://doi.org/10.1111/j.1540-8159.2010.02885.x.

20. Sears, S. F., Sowell, L. D., Kuhl, E. A., Kovacs, A. H., Serber, E. R., Handberg, E., et al. (2007). The ICD shock and stress management program: A randomized trial of psychosocial treatment to optimize quality of life in ICD patients. Pacing and Clinical Electrophysiology, 30(7), 858-864. https://doi.org/10.111 1/j.1540-8159.2007.00773.x.

21. Kamphuis, H. C., de Leeuw, J. R., Derksen, R., Hauer, R. N., \& Winnubst, J. A. (2003). Implantable cardioverter defibrillator recipients: Quality of life in recipients with and without ICD shock delivery: A prospective study. Europace, 5(4), 381-389. https://doi.org/10.1016/s1099-5129(03)00078-3.

22. Friedmann, E., Thomas, S. A., Inguito, P., Kao, C. W., Metcalf, M., Kelley, F. J., et al. (2006). Quality of life and psychological status of patients with implantable cardioverter defibrillators. The Journal of Interventional Cardiac Electrophysiology, 17(1), 65-72. https://doi.org/10.1007/s10840-006-9053-1.

23. Zayac, S., \& Finch, N. (2009). Recipients' of implanted cardioverter-defibrillators actual and perceived adaptation: A review of the literature. Journal of the American Association of Nurse Practitioners, 21(10), 549-556. https://doi.org/10.111 1/j.1745-7599.2009.00445.x.

24. Al-Rawashdeh, S., Alshraifeen, A., Rababa, M., \& Ashour, A. (2020). Hope predicted quality of life in dyads of communitydwelling patients receiving hemodialysis and their family caregivers. Quality of Life Research, 29(1), 81-89. https://doi. org/10.1007/s11136-019-02378-4.

25. Friedman, D. J., Parzynski, C. S., Heist, E. K., Russo, A. M., Akar, J. G., Freeman, J. V., et al. (2018). Ventricular fibrillation conversion testing after implantation of a subcutaneous implantable cardioverter defibrillator: Report from the national cardiovascular data registry. Circulation, 137(23), 2463-2477. https:// doi.org/10.1161/circulationaha.117.032167.

26. Priori, S. G., Blomstrom-Lundqvist, C., Mazzanti, A., Blom, N., Borggrefe, M., Camm, J., et al. (2015). 2015 ESC Guidelines for the management of patients with ventricular arrhythmias and the prevention of sudden cardiac death: The Task Force for the Management of Patients with Ventricular Arrhythmias and the Prevention of Sudden Cardiac Death of the European Society of Cardiology (ESC)Endorsed by: Association for European Paediatric and Congenital Cardiology (AEPC). Europace, 17(11), 1601-1687. https://doi.org/10.1093/europace/euv319. 
27. Al-Khatib, S. M., Stevenson, W. G., Ackerman, M. J., Bryant, W. J., Callans, D. J., Curtis, A. B., et al. (2018). 2017 AHA/ ACC/HRS guideline for management of patients with ventricular arrhythmias and the prevention of sudden cardiac death: Executive summary: A Report of the American College of Cardiology/American Heart Association Task Force on Clinical Practice Guidelines and the Heart Rhythm Society. Heart Rhythm, 15(10), e190-e252. https://doi.org/10.1016/j.hrthm.2017.10.035.

28. Aaronson, N. K., Muller, M., Cohen, P. D., Essink-Bot, M. L., Fekkes, M., Sanderman, R., et al. (1998). Translation, validation, and norming of the Dutch language version of the SF-36 Health Survey in community and chronic disease populations. Journal of Clinical Epidemiology, 51(11), 1055-1068. https:// doi.org/10.1016/s0895-4356(98)00097-3.

29. Ware, J. E., Jr., \& Sherbourne, C. D. (1992). The MOS 36-item short-form health survey (SF-36). I. Conceptual framework and item selection. Medical Care, 30(6), 473-483.

30. Yesavage, J. A., \& Sheikh, J. I. (1986). 9/Geriatric Depression Scale (GDS). Clinical Gerontologist, 5(1-2), 165-173. https:// doi.org/10.1300/J018v05n01_09.

31. Steca, P., Monzani, D., Greco, A., Chiesi, F., \& Primi, C. (2015). Item response theory analysis of the life orientation test-revised: Age and gender differential item functioning analyses. Assessment, 22(3), 341-350. https://doi.org/10.1177/107319111454447 1.

32. Scheier, M. F., Carver, C. S., \& Bridges, M. W. (1994). Distinguishing optimism from neuroticism (and trait anxiety, self-mastery, and self-esteem): A reevaluation of the Life Orientation Test. Journal of Personality and Social Psychology, 67(6), 1063-1078.

33. Kim, D. H., Park, J. I., Lee, J. P., Kim, Y. L., Kang, S. W., Yang, C. W., et al. (2020). The effects of vascular access types on the survival and quality of life and depression in the incident hemodialysis patients. Renal Failure, 42(1), 30-39. https://doi. org/10.1080/0886022x.2019.1702558.
34. Wong, F. M., Sit, J. W., Wong, E. M., \& Choi, K. C. (2014). Factors associated with health-related quality of life among patients with implantable cardioverter defibrillator: Identification of foci for nursing intervention. Journal of Advanced Nursing, 70(12), 2821-2834. https://doi.org/10.1111/jan.12434.

35. Lewin, R. J., Coulton, S., Frizelle, D. J., Kaye, G., \& Cox, H. (2009). A brief cognitive behavioural preimplantation and rehabilitation programme for patients receiving an implantable cardioverter-defibrillator improves physical health and reduces psychological morbidity and unplanned readmissions. Heart, 95(1), 63-69. https://doi.org/10.1136/hrt.2007.129890.

36. Irvine, J., Dorian, P., Baker, B., O’Brien, B. J., Roberts, R., Gent, M., et al. (2002). Quality of life in the Canadian Implantable Defibrillator Study (CIDS). American Heart Journal, 144(2), 282-289. https://doi.org/10.1067/mhj.2002.124049.

37. Schron, E. B., Exner, D. V., Yao, Q., Jenkins, L. S., Steinberg, J. S., Cook, J. R., et al. (2002). Quality of life in the antiarrhythmics versus implantable defibrillators trial: Impact of therapy and influence of adverse symptoms and defibrillator shocks. Circulation, 105(5), 589-594. https://doi.org/10.1161/hc0502.103330.

38. Fitchet, A., Doherty, P. J., Bundy, C., Bell, W., Fitzpatrick, A. P., \& Garratt, C. J. (2003). Comprehensive cardiac rehabilitation programme for implantable cardioverter-defibrillator patients: A randomised controlled trial. Heart, 89(2), 155-160. https://doi. org/10.1136/heart.89.2.155.

Publisher's Note Springer Nature remains neutral with regard to jurisdictional claims in published maps and institutional affiliations. 